\title{
Evaluation of Large-Scale Housing Projects in Terms of Their Compatibility to Criteria of Environmental Design
}

\author{
Yasser Aref ${ }^{1}$ and Tasneem M. Khalii ${ }^{2}$ \\ 1. Department of Architecture, Faculty of Engineering, Menoufia University, Menoufia 32511, Egypt \\ 2. Water and Sewage Company, Menoufia 32511, Egypt
}

\begin{abstract}
The design and execution of large-scale housing projects always have negative environmental impacts in terms of excessive consumption of non-renewable energy resources and environmental pollution. These negative impacts are multiplied in the case of large-scale housing projects where a large number of standardized units are implemented in a repeated manner. This proposed paper will study and evaluate the environmental impacts of large-scale housing projects according to criteria of environmental design. The case study project is Haram City that is a housing project for small low-income families. The project consists of 50,000 housing units and is located in 6th of October City, which has a hot dry desert climate that necessitates special design considerations and applications of environmental design concepts. The project will be analyzed and evaluated in terms of site layout, design of buildings, orientation, materials used, construction techniques, thermal behavior, landscaping, etc.
\end{abstract}

Key words: Green architecture, environmentally-friendly buildings, low-cost housing projects, environmental design concepts.

\section{Introduction}

The design and construction of buildings usually cause a lot of environmental degradations. Buildings consume large amounts of energy and water, and they produce harmful wastes. Many buildings create unhealthy internal environments that cause inhabitants to become sick and uncomfortable physically and psychologically. The processes of design and construction of buildings need to be reconsidered to assess their impact on health and the environment. These processes need to be evaluated in accordance to environmental-friendly buildings standards. This paper aims to achieve some conclusions and strategies that can be recommended and applied to the future designs of housing projects. To achieve these goals, the research will review general concepts of green architecture and concepts of environmentally-friendly designs, setting up the evaluation criteria for environmentally-friendly designs and, finally, study in

Corresponding author: Yasser Aref, associate professor, research fields: sustainable architectural and conservation of cultural heritage. detail one of the large-scale housing projects in Egypt.

\section{Characteristics of Sick Buildings}

Sick buildings have three main characteristics:

(1) They consume excessive amounts of energy and natural resources, i.e., energy used to construct a building can be equal to the required energy to run it for a period of 10 20 years [1]. The construction industry consumes about $40 \%$ of the total energy consumption in the world. Moreover, the building sector, including all processes of construction, manufacturing, operating and others, consumes annually about $16 \%$ of potable water [2];

(2) The construction industry is responsible for one third of the amount of carbon dioxide emissions stored and about two thirds of the amount of acid rain from sulfur dioxide and nitrogen oxide [2]. This causes environmental pollution and disturbs the ecosystem;

(3) The negative impact on human health is caused. Some building materials, such as polyurethane, foam wallpaper, vinyl and petrochemical-based paints or plastics, can be harmful to human health [3]. Moreover, some soils on the building site may emit 
radon [4]. In order to avoid the disadvantages of the sick buildings, the concept of green architecture and its principles must be studied and applied.

\section{Principles of Green Architecture}

Green architecture is a process of designing buildings with respect for the environment. It aims to reduce the consumption of energy, materials and resources while maximizing harmony with nature [3]. Green architecture has five main principles.

\subsection{Saving Energy}

Green architecture has a principle of saving energy by reducing the energy required in the construction of the buildings, increasing energy efficiency, depending on natural energies, such as sun, wind, waves, biomass and water [5], raising the efficiency of the surrounding of the building and optimizing the building orientation [3].

\subsection{Adapting to Local Climate}

The building design should provide protection from the climate and provide a suitable internal atmosphere for human activities [6].

\subsection{Minimizing the Consumption of New Resources}

Green buildings minimize the consumption of new resources by using recyclable and biodegradable building materials [3]. They also use durable local building materials to minimize the energy used for transportation and have a long lifespan which requires less maintenance [2]. Water consumption can be reduced by recycling and treating waste water, which is known as grey water, and also collecting and reusing rainwater [5].

\subsection{Respect of Surrounding Site}

This is achieved by minimizing substantial changes to the site, lowering the footprint of the building, avoiding building on agricultural lands and minimizing pollution during construction process [7].

\subsection{Comprehensive Design}

The principles of green architecture must be applied in an integrated manner during the design and construction processes, taking into consideration the wider context within a comprehensive planning approach [6].

\section{Case Study}

In this part, the project of Haram City (or Pyramid City) will be studied and evaluated for its achievement of the objectives and principles of green architecture and to examine how far it is environmentally-friendly. This project was selected because it is a new, large housing project aimed for low income families. Due to the large number of units (50,000 units), the impact of the project on site, users and the environment is critical.

In 2006, OHC (Orascom Housing Communities), in a joint venture with Homex, an integrated home development company focused on affordable housing headquartered in Mexico, launched the project. For this project, $\mathrm{OHC}$ was allocated approximately $8,400,000 \mathrm{~m}^{2}$ of land in 6th of October City, in the vicinity of Cairo. The town infrastructure will include educational, health, commercial and entertainment services. Actual construction started in spring 2007 and the city was inhabited in the fall of 2008 . Construction work on two zones out of the planned eight zones was completed, and the main water line, electricity supply and sewage plants have been secured.

\section{Analysis of Criteria of an Environmentally-Friendly Building}

\subsection{Using Natural Energy}

\subsubsection{Building Orientation}

It is preferable to position the longest façades of the building on the east-west axis, i.e., the north façade is exposed to the lowest amount of heat in summer while the south façade exposed to the highest amount of 


\section{Evaluation of Large-Scale Housing Projects in Terms of Their Compatibility to Criteria of Environmental Design}

heat in winter [8]. Building orientation has not been highly considered in the planning of Haram City, where the typology of units consists of four units which are assembled around a staircase (Fig. 1). Setting the layout of the blocks in rows resulted in opposite directions for units.

\subsubsection{The Building Form}

In hot arid areas, the ideal ratio of the two sides of buildings ranges from $1: 1.3$ to $1: 1.6$. This ratio deters the heat in the summer and stores it in the winter [8]. In the studied model, the elongation percentage is 1:1.4 which lays within the recommended ratios (Fig. 2).

\subsubsection{The Building Mass}

Shadow on buildings can save up to more than $30 \%$ in consumed energy [6]. Shadow can be maximized by articulating the mass of the buildings and avoiding using flat roofs [8]. Building with domes and vaults cast large amounts of shadow (Figs. 3 and 4). The housing units in Haram City project have a one-sided open courtyard, $4 \mathrm{~m}$ wide. The court provides shade and allows for wind movement and is used as a bioclimatic feature. Windows are recessed about $10 \mathrm{~cm}$. The ground floor is protected by the balcony of

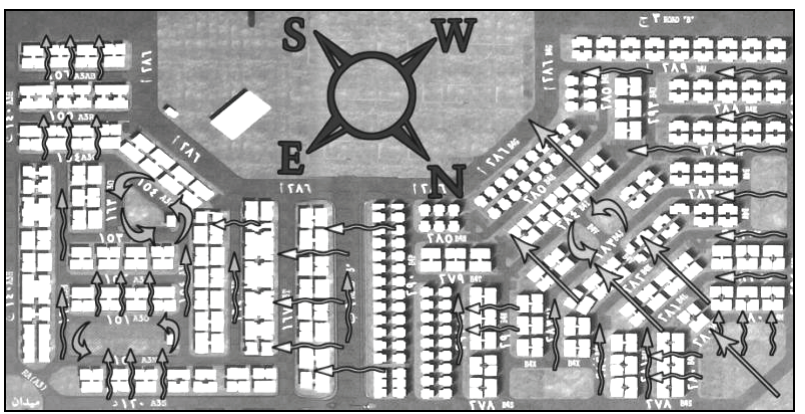

Fig. 1 The direction of wind around site area.

Source: the authors, base master plan administration of Haram City.

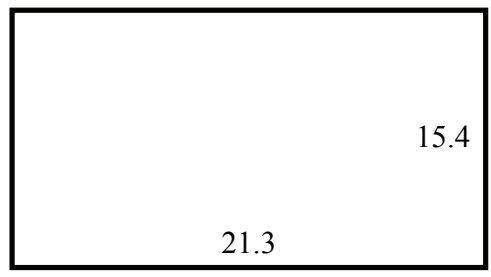

Fig. 2 Building elongation (units in $\mathbf{m}$ ). Source: the authors. first floor (Fig. 5). Experiments state that when the external façade area $(F)$ is less than the volume $(V)$, thermal exchange with the external surrounding is minimal. This results in saving energy. This phenomenon is applied in designing attached or semi-attached buildings [9]. For the Haram City Project:

- External surface: $F=6,011.6 \mathrm{~m}^{2}$;

- Volume of the housing block: $V=6,325 \mathrm{~m}^{3}$;

- $F / V=0.9$.

According to this result, the buildings of the project fall within the recommended ratio which implies that they use less energy for conditioning the internal spaces.

\subsubsection{Organization of Internal Space}

Services are preferably located to the south and west to insulate heat while bedrooms and living spaces

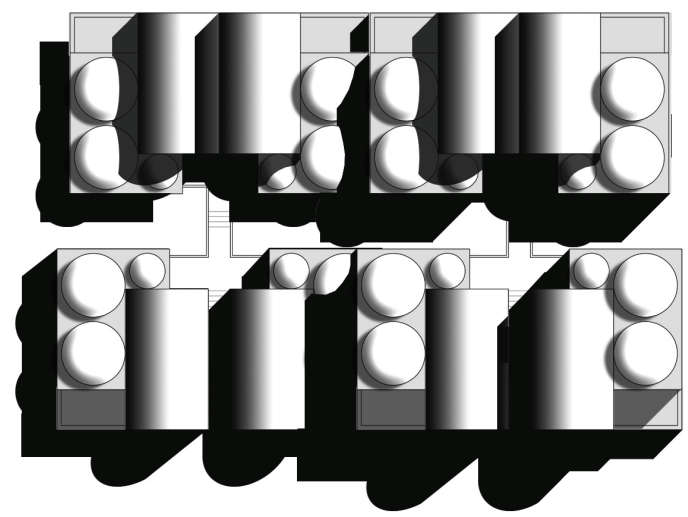

Fig. 3 Shadows resulted from the differences of building height.

Source: the authors.

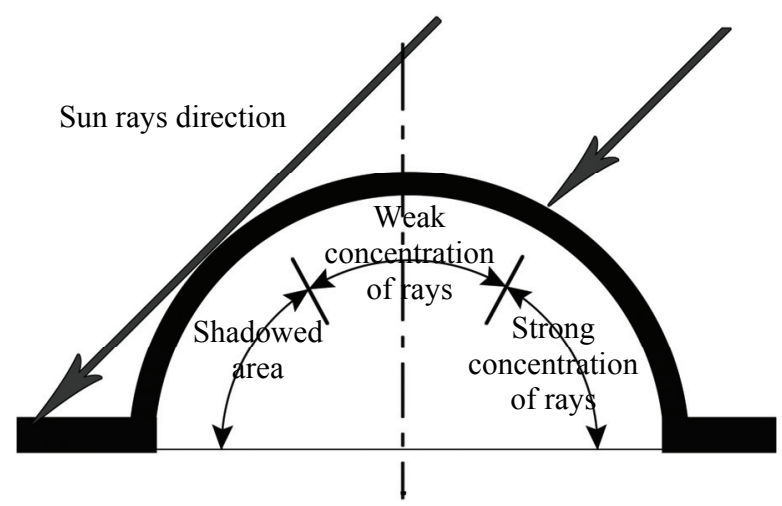

Fig. 4 The effect of the surface shape on shadows amount $[8]$. 


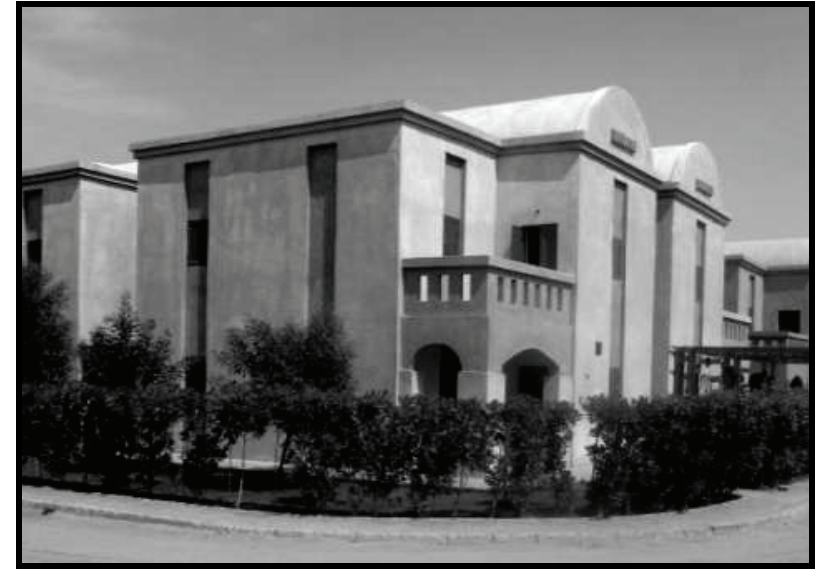

Fig. 5 Shadows falling on the building façade. Source: the authors.

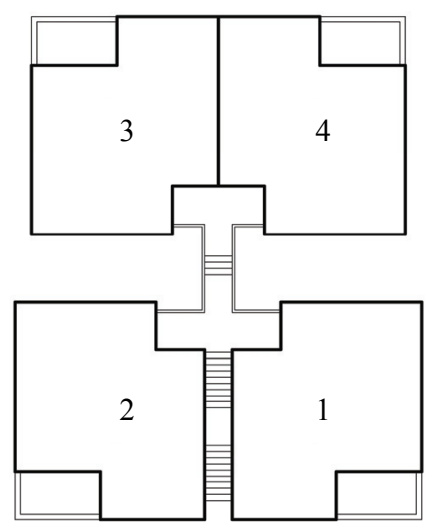

Fig. 6 Configuration of housing units in the upper floor. Source: the authors.

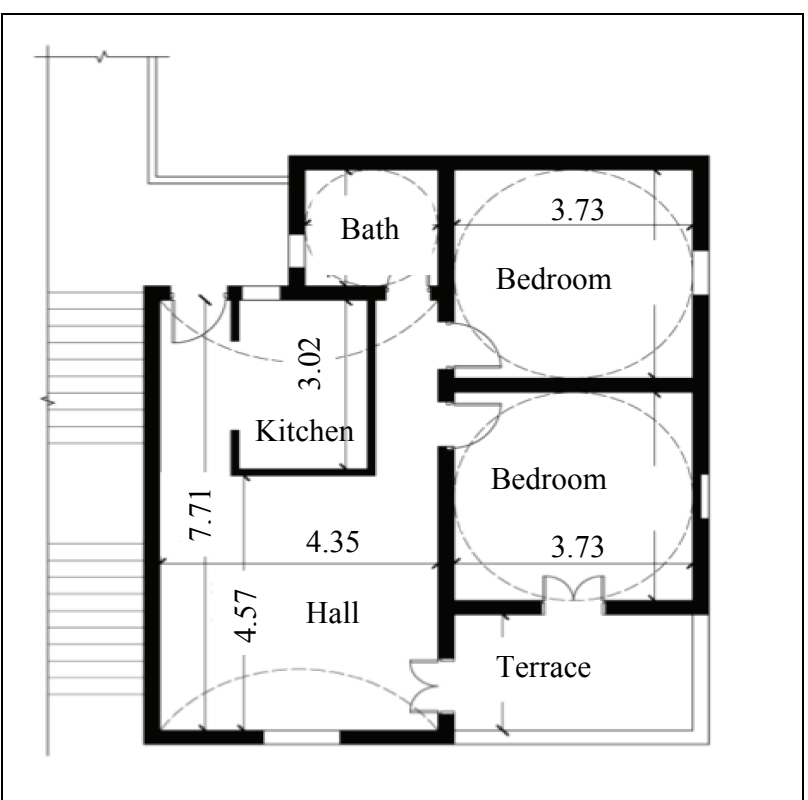

Fig. 7 Plan for the first floor (units in $\mathbf{m}$ ). Source: project administration of Haram City. are preferably be located to the north-east or east where they catch cool breezes and receive natural light without heat gain [8]. Consequently, some of the units of Haram City achieved the proper orientation while others did not. This is, of course, due to the large number of units and other planning considerations (Figs. 6 and 7).

\subsubsection{Walls}

Internal and external walls should be thick and massive in the hot, dry climate. Wall thickness of Haram City buildings is $22 \mathrm{~cm}$. Walls are made of red clay bricks which have a large thermal capacity $\left(25.2 \mathrm{~W} / \mathrm{m}^{2} \cdot{ }^{\circ} \mathrm{C}\right)$ and have a delay of the thermal transition time of approximately $4 \mathrm{~h}$ and $16 \mathrm{~min}$ [10]. The higher the thermal capacity of the wall, the less heat transmission inside the building [11]. The minimal total cost per unit area of the walls, including brick and mortar price, as well as workers salaries, plus operating costs is equivalent to a wall thickness of 0.34 m, i.e., one and a half bricks (Fig. 8) [12]. The surrounding land surface and landscaping in Haram City, which is treated by planting green areas of grass, scatters solar radiation reflected from the walls.

\subsubsection{Openings}

To allow for maximum air circulation, it is recommended that inlet and outlet openings have different areas. The air that enters opening should be less than the air from outlet opening. The glass area should not be more than $10 \%$ of the floor area and it is favorable to use sun breakers and curtains to minimize thermal gain [9]. Most of the rooms of the Haram City buildings have one opening while living rooms have two openings in two perpendicular walls. The height of the windows from the floor is $1.10 \mathrm{~m}$. The area of glass is about $5 \%$ of the floor area and no sun breakers are used.

\subsubsection{Roofs}

The gain of thermal energy through the ceiling depends on the thermal performance of the material used for its construction [9]. In Haram City, the roofs are made of red bricks that have low heat absorption. 


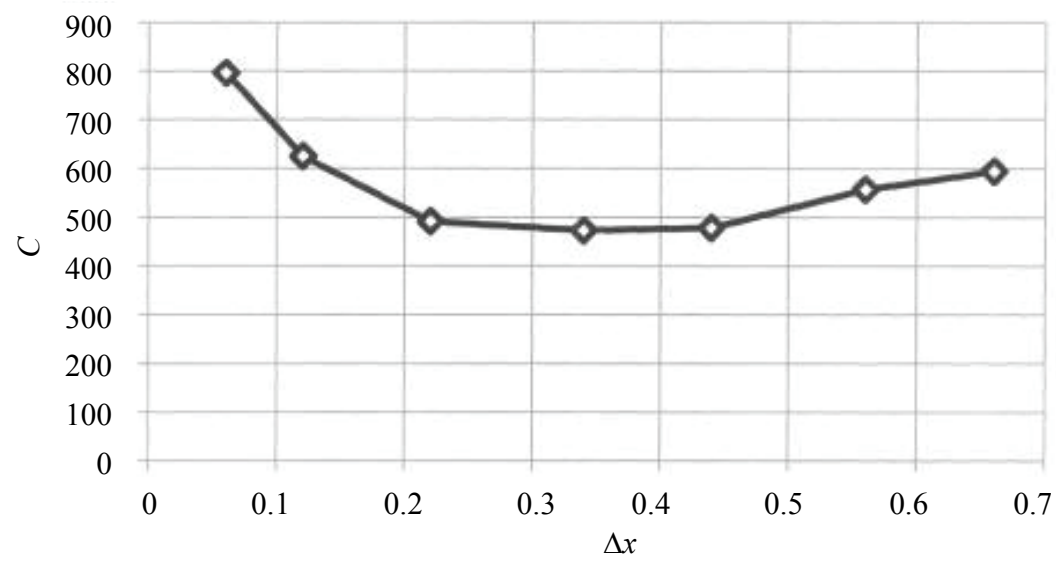

Fig. 8 Relationship between wall thickness ( $x$-axis) and total cost per unit of surface area (y-axis). Source: the authors.

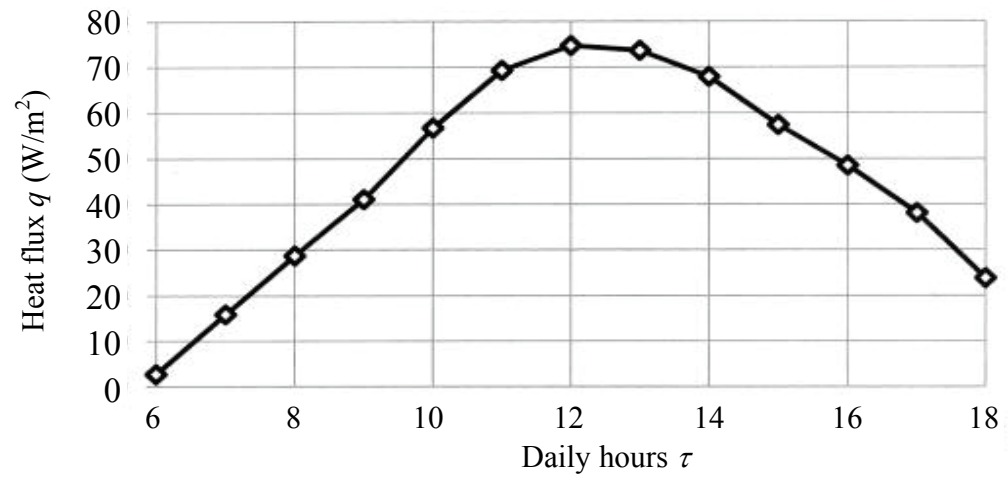

Fig. 9 Variation of heat flux through the dome during $24 \mathrm{~h}$. Source: the authors.

The vaulted shape of the roofs increases the speed of the air passing on its curved surfaces. This cools the inside of the building; The vaults have no openings for the hot air to be discharged during the night [13]. Based on Refs. [12, 14], Fig. 9 illustrates heat loss through the domes of the buildings during $24 \mathrm{~h}$.

\subsection{Environmentally-Friendly Building Materials}

Building materials should be
environmentally-friendly. They must consume low energy in the stage of manufacturing, installation and maintenance. Building materials should also minimize internal pollution of the building. The energy consumption of a building material is based on the total energy (combination of electrical energy and thermal energy) needed for producing a unit weight of the material. The energy consumption of producing a unit weight of bricks is $2,320 \mathrm{~W} \cdot \mathrm{h} / \mathrm{t}$ [3]. The main building material used for the foundations, walls and roofs are locally produced by red bricks, which are durable and environmentally-friendly. The transfer of bricks from nearby Bani-Sewaif's and El-Saf's factories does not consume large amounts of energy. Acrylic paint is used for internal finishing, and ceramic tiles are used for floorings; Both are not environmentally-friendly building materials. The first contains chemicals and the second consumes large amounts of energy during production phase that are harmful to the environment.

\subsection{Saving Water}

Supplying water consumes energy for collecting, purifying and pumping to the buildings. Haram City is applying concepts of reusing water. Sewage from basins, 


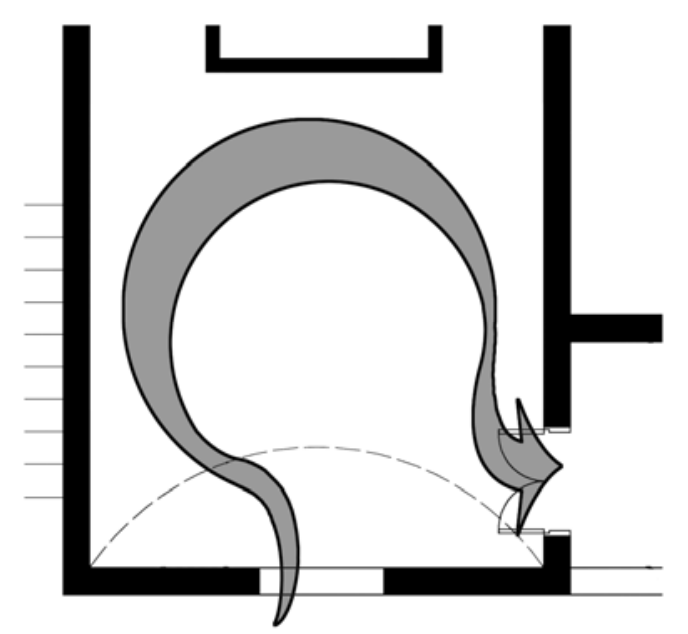

Fig. 10 Air movement inside a room with two openings. Source: the authors.

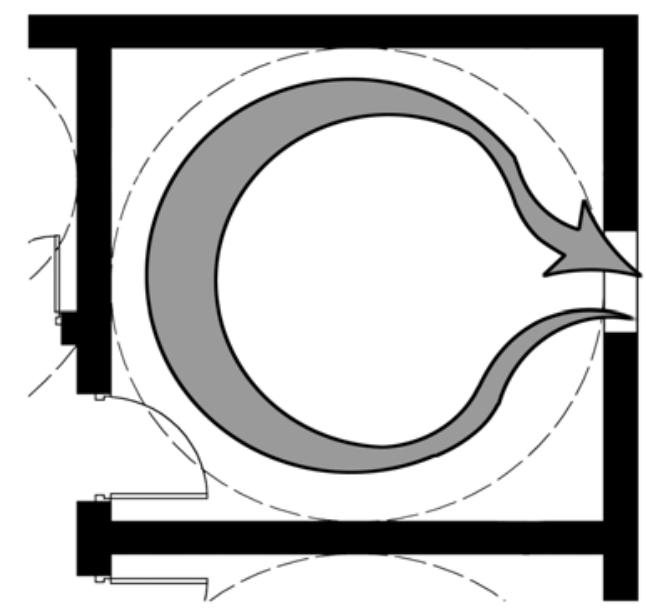

Fig. 11 Air movement inside a room with one opening. Source: the authors.

kitchens and showers are collected in a special tank, treated and reused in watering gardens and pumped again to flush tanks.

\subsection{Air Quality}

Pollution of air inside a building is a result of using chemicals in building materials and finishing, and also in poorly ventilated buildings [3]. For the openings layout in Haram City buildings, most of the openings are facing prevailing winds (Figs. 10 and 11). Some rooms have more than one opening. This allows more active air circulation. Air conditioners are rarely used in Haram City buildings. This prevents the spread of bacteria and fungi. Even though porous bricks are used in the building, they are covered which results in making them less permeable and do not retain moisture. This did not balance the proportion of moisture in the surrounding dry climate [15].

\subsection{Natural Lighting}

Openings represent $8 \%$ of room floor area and $10 \%$ of bathroom area. These percentages are in accordance with local building codes [16]. Roofs, walls and window frames are textured and painted in light colors to reflect the sun and reduce glare. Clear glass panes are used for the windows. This allows the maximum quantity of the light into the internal space with the minimum blurring. The glass thickness is $3 \mathrm{~mm}$, its reflection factor is $7 \%$, its absorption is $8 \%$ and its transmission is $85 \%$ [13].

\subsection{Acoustic Design}

The efficiency of walls in preventing noise transmission depends on their mass and thickness. On the other hand, floors depend on the degree of surface absorption [3]. For Haram City buildings, the thickness of the wall bricks is $22 \mathrm{~cm}$; This is not enough to insulate noise. In Haram City, bedrooms are placed inside and overlook pathways between units; Service areas overlook the stairs, while living rooms overlook the street. This arrangement provides bedrooms with the required sound insulation.

\subsection{Safety Design of the Building}

The site of Haram City is a combination of sandy and rocky soils. The project is laid out with the minimum intervention of the land, following natural contours. A belt of trees is planted around the buildings to be fenders against unwanted winds. The design of buildings considers earthquake resistance in terms of regular mass, using one construction system, in which the building length is less than 4 times its width and the limited height [17]. For fire resistance, the stair serves four flats. The stair is compatible with 
the fire codes as they have a width of $1.20 \mathrm{~m}$ and is divided into two flights, each flight consists of 10 steps separated by a landing of $1.20 \mathrm{~m} \times 1.20 \mathrm{~m}$ [18], in addition to fire extinguishers which are distributed all over the project.

\subsection{Architectural Style Compatible with the Local Character}

Egypt has a hot dry climate, therefore, in Haram City, thick walls are used. Roofs are covered by domes and vaults. Local bricks are used as the main building material. These elements adapt to climate, protect from sun rays, provide shade and cool the atmosphere. They are also compatible with the local architectural character and are inspired by the vernacular architecture of the area developed by Hassan Fathi and Ramsis Wissa Wassef in Harrania and Giza.

\subsection{Landscaping and Outdoor Spaces}

Grass can filter the air from dust, smog and waste, and it also improves the hot climate by $30 \%$ [7]. It also minimizes relative humidity and glare [19]. Walkways are made of natural stone masonry. Vegetation is used wisely with Ficus fences around the blocks and trees planted in each garden (Fig. 12).

\subsection{Master Plan}

The master plan of the project is not compact. However, buildings are quite close to each other, shading each other and also providing shade for the narrow walkways. Spaces in front of buildings consist of large green areas and parking. Each cluster of buildings is grouped around a green public space. These public spaces are interrelated by foot paths, providing a pedestrian network. The height of the buildings ranges from one floor to four floors and has a homogeneous visual character.

\section{Findings}

Buildings should be friendly to the environment by

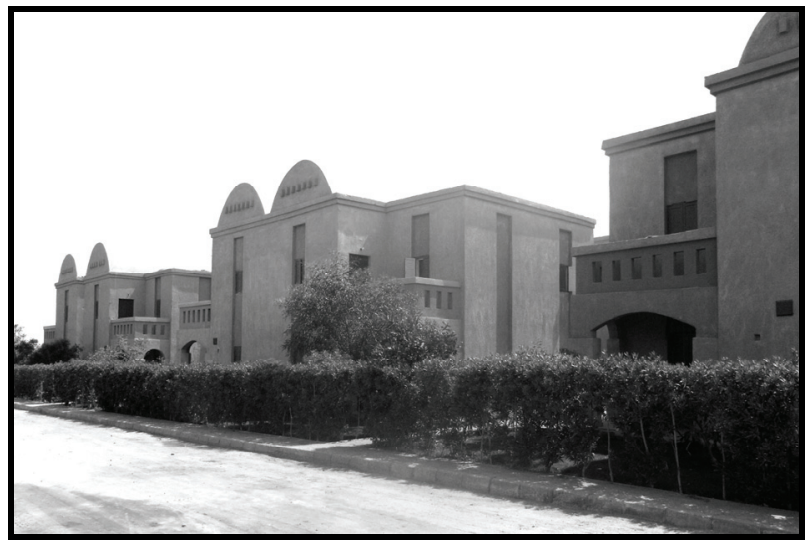

Fig. 12 The use of shrubs and trees for shading of building façades.

Source: the authors.

applying the standards of environmental design. Some of these standards are achieved by Haram City which leads to the following conclusions:

- Buildings are oriented towards several directions. The plan is rectangular with a ratio of 1:1.4. It is directed along the east-west axis. The proper orientation for some buildings is achieved;

- The proportion between the external areas, which are exposed to weather conditions, to the total volume is 0.9 ;

- Local red clay bricks with a width of $22 \mathrm{~cm}$ are used as bearing wall structure system. Red bricks are a local building material with a low consumption of energy which causes minimum pollution. However, the best thickness for walls in terms of thermal comfort and optimum cost should have been $34 \mathrm{~cm}$. Moreover, walls are not thick enough to prevent the transmission of noise;

- External walls and roofs are painted with light colors to reflect heat and sun rays;

- Roofs are domed and vaulted to cast shadow to prevent direct sun exposure and create shade articulated building forms;

- The landscape is planted with trees and some shrubs to control the circulation of the air around or into the building. This also reduces the heat gain of the walls. This leads to a saving of about $60 \%$ of the consumption of energy used for cooling or heating; 
- The use of recycled treated grey water for irrigation and flushing is achieved;

- The architectural style of the buildings is compatible with the local environment through using roofs with domes and vaults and local materials;

- Even though the layout of the site is not compact, the buildings are close enough to provide shaded and narrow walkways.

\section{Recommendations}

Following recommendations are given to future researches:

- To achieve the ideal orientation for units, a cluster of housing units should be designed with optimum orientation for each unit, then this cluster is repeated;

- We can utilize renewable energy sources either directly or indirectly while preparing the architectural and mechanical designs of the buildings as it contributes to the reduction of energy consumption in buildings;

- Applying concepts of energy conservation in design and construction of housing projects should not deter from providing the required services, comfort and architectural aesthetics;

- Different construction methods and building materials can be used in the same building according to the type and use of internal spaces. The spaces used throughout the day should have thick walls with large thermal capacity. Spaces with little use may be of light materials with low thermal capacity;

- In designing large-scale housing projects, plans should be flexible and provide the possibility of vertical or horizontal extension to accommodate the increase of family size;

- Using high openings in walls and vaults provides heat discharge and air circulation. The openings size should prevent the entry of direct sunlight and rain;

- Walls must be designed to reach the highest possible efficiency in terms of providing thermal comfort while saving energy consumption, as well as cost. It was found that the lowest total cost for a wall to save thermal comfort can be obtained by designing walls of 34-cm thickness.

\section{References}

[1] Vale, B., and Vale, R. 1991. Green Architecture. London: Thames and Hudson.

[2] Al Rafai, M. 2007. "Technical View for Drafting Permanent Reconstruction from Local View." M.Sc. thesis, Cairo University.

[3] Waziri, Y. 2007. Environmentally Friendly Architectural Design-Towards Green Reconstruction. Cairo: General Egyptian Authority for Books.

[4] Pearson, D. 1991. The Natural House. London: Conran Octopus Ltd.

[5] Bauer, M., Mosle, P., and Schwarz, M. 2010. Green Building-Guidebook for Sustainable Architecture. Berlin: Springer.

[6] El Shahry, A. 2008. "Building Technology and Its Rule in Achieving Thermal Comfort inside Architectural Spaces." M.Sc. thesis, Cairo University.

[7] Abdou, O. 2000. "Green Architecture: A Holistic Approach." Medina Magazine 11: 28-31.

[8] Al Wakeel, S., and Serag, M. 1985. Climate and Hot Area Architecture. Cairo: Al Tobgy Press.

[9] Afify, H. M. 2001. "Design Considerations for Rural Housing from the Perspective of Environmental Engineering and Energy Self-Sufficiency." Presented at the 3rd Conference for the Development of the Egyptian Countryside, Cairo, Egypt.

[10] Aziz, S. 1988. "Thermal Attitude Evaluation as a Tool for Designing Housing Complexes in Egypt.” Ph.D. thesis, Cairo University.

[11] Watson, D., and Labs, K. 1983. Climatic Design. New York: McGraw-Hill Book Company.

[12] Group of Energy and Reconstruction Experts. 1998. Reconstruction and Energy Guide. Cairo: Energy Planning Department.

[13] Ali, A. M. 2006. Climate and Desert Reconstruction. Assuit: Assuit University.

[14] Selim, R. 2003. "The Impact of Building Technology Used in Outer of the Building on Conserving Energy." M.Sc. thesis, Cairo University.

[15] Baggs, S., and Baggs, J. 1996. The Healthy House. London: Thames and Hudson.

[16] Ministry of Housing, Utilities and Urban Development. 2008. Building Law (No. 119, 2008). Cairo: Ministry of Housing, Utilities and Urban Development.

[17] Housing and Building National Research Center. 2005. Egyptian Code for Designing and Constructing Buildings, No. 204. Cairo: Today's News Press. 
Compatibility to Criteria of Environmental Design

[18] Housing and Building National Research Center. 2007. Egyptian Code for Fire Protection: Part one. Cairo: Republic House Press.
[19] Abou Seda, H., and Badr, B. 2002. Environment Reconstruction Profession. Cairo: Arab World House. 